\title{
BMJ Open Improving regional care in the last year of life by setting up a pragmatic evidence-based Plan-Do-Study-Act cycle: results from a cross- sectional survey
}

\author{
Raymond Voltz, ${ }^{1,2,3,4}$ Gloria Dust (10) , ${ }^{1}$ Nicolas Schippel, ${ }^{5}$ Stefanie Hamacher, ${ }^{6}$ \\ Sheila Payne, ${ }^{7}$ Nadine Scholten (1) ${ }^{5}$ Holger Pfaff, ${ }^{5}$ Christian Rietz, ${ }^{8}$ \\ Julia Strupp (D) , ${ }^{1}$ On behalf of The CoRe-Net Co-applicants
}

To cite: Voltz R, Dust G, Schippel N, et al. Improving regional care in the last year of life by setting up a pragmatic evidence-based Plan-Do-Study-Act cycle: results from a crosssectional survey. BMJ Open 2020;10:e035988. doi:10.1136/ bmjopen-2019-035988

- Prepublication history for this paper is available online. To view these files, please visit the journal online (http://dx.doi. org/10.1136/bmjopen-2019035988).

RV and GD contributed equally.

Received 25 November 2019 Revised 27 August 2020 Accepted 01 October 2020

Check for updates

(C) Author(s) (or their employer(s)) 2020. Re-use permitted under CC BY-NC. No commercial re-use. See rights and permissions. Published by BMJ.

For numbered affiliations see end of article.

Correspondence to

Gloria Dust;

gloria.dust@uk-koeln.de

\section{ABSTRACT}

Objectives To set up a pragmatic Plan-Do-Study-Act cycle by analysing patient experiences and determinants of satisfaction with care in the last year of life.

Design Cross-sectional postbereavement survey.

Setting Regional health services research and development structure representing all health and social care providers involved in the last year of life in Cologne, a city with 1 million inhabitants in Germany.

Participants 351 bereaved relatives of adult decedents, representative for age and gender, accidental and suspicious deaths excluded.

Results For the majority (89\%) of patients, home was the main place of care during their last year of life. Nevertheless, $91 \%$ of patients had at least one hospital admission and $42 \%$ died in hospital. Only $60 \%$ of informants reported that the decedent had been told that the disease was leading to death. Hospital physicians broke the news most often (58\%), with their communication style often (30\%) being rated as 'not sensitive'. Informants indicated highly positive experiences with care provided by hospices ( $89 \%$ 'good') and specialist palliative home care teams ( $87 \%$ 'good'). This proportion dropped to $41 \%$ for acute care hospitals, this rating being determined by the feeling of not being treated with respect and dignity $(\mathrm{OR}=23.80,95 \% \mathrm{Cl} 7.503$ to 75.498$)$ and the impression that hospitals did not work well together with other services $(\mathrm{OR}=8.37,95 \% \mathrm{Cl} 2.141$ to 32.71$)$.

Conclusions Following those data, our regional priority for action now is improvement of care in acute hospitals, with two new projects starting, first, how to recognise and communicate a limited life span, and second, how to improve care during the dying phase. Results and further improvement projects will be discussed in a working group with the city of Cologne, and repeating this survey in 2 years will be able to measure regional achievements. Trial registration number DRKS00011925.

\section{INTRODUCTION}

Patients in their last year of life may be regarded as vulnerable because most of them

\section{Strengths and limitations of this study}

- This study presents a multidimensional and comprehensive assessment of care provided in multiple settings in the entire last year of life.

- It describes a pragmatic template for determining regional improvement priorities based on patient experiences using a city-wide health services research and development structure (Plan-Do-Study-Act cycle).

- The reports of relatives cannot be seen as a direct substitute for a self-assessment of patients, although a good agreement has been shown on service evaluations and observable symptoms.

- The retrospective approach bypasses the difficult task of identifying the terminally ill, avoids putting an additional burden on very sick participants and minimises missing data due to poor functional status.

need complex care provided by multiple health and social care practitioners. ${ }^{1}$ Their needs are often not sufficiently met, especially in settings outside specialist palliative and hospice care. ${ }^{23}$ Due to the fact that they are often dependent on others to meet their physical care needs, they can deteriorate unpredictably and rapidly, and their ability to make informed choices may be reduced due to cognitive impairment. ${ }^{4}$ Care transitions as well as non-beneficial treatments are common, which may compromise human dignity and quality end-of-life care. ${ }^{5}$ In Germany, the evidence-based guideline 'Palliative care' was published in 2015 to promote quality end-oflife care by all healthcare professionals. This aim may be achieved by "providing palliative care services in both a timely manner and in accordance with the affected persons' needs, treating the common symptoms according 
to current scientific evidence and clinical expertise, enabling conversations with patients and their families to be held and treatment goals to be set together, ensuring that support in the dying phase can be appropriately and optimally given'. ${ }^{2}$

Evidence shows that most people prefer their home as place of death. ${ }^{8}$ This also applies to Germany. However, almost one person in two dies in hospital and one-third in care home. ${ }^{9}$ Fragmentation of multidisciplinary service provision is one major barrier to adequately addressing patients' needs and preferences. ${ }^{10}$ Data on patients' and their families' perceptions are essential in order to understand these issues and to inform quality improvements. The last year of life can obviously only be objectively determined in retrospect, but it has to be managed prospectively. Adding palliative care in the last 12-24 months of life has proven to be greatly beneficial. ${ }^{11} 12$ Therefore, consideration also needs to be given to the introduction of these services. However, the majority of surveys focuses on the dying phase or the last weeks to months of life and only a few studies have compared end-of-life care across different settings. ${ }^{13-16}$ Care in the last year of life encompasses a wide range of services necessitating a multidimensional and comprehensive assessment approach. ${ }^{14}$ This comprises the measurement of patients' experiences of the communication of a life-limiting disease ('transition into the last year of life'), transitions between healthcare settings ('transitions within the last year of life') and the dying phase ('transition into death and a new phase of life for bereaved relatives'). For Germany, data on patients' perceptions of their experience of care in the last year of life that go beyond diagnoses and care settings are still rare.

Germany possesses a well-defined, government-led strategy for the development and promotion of national palliative care and performed well in the 2015 Quality of Death Index (position seven in the global rank of overall scores).${ }^{17}$ Based on the patients' needs, they may receive generalist palliative care (eg, provided in a general hospital ward, a nursing home, by a general practitioner (GP) or a nursing service at home) or specialist palliative care provided by specialist personnel with expert knowledge, skills and attitudes (eg, delivered in a hospital palliative care unit, a hospice or by a specialist palliative home care team). Hospice care in Germany refers to care provided in an inpatient facility. In addition, hospice services delivered by volunteers may support the patients and their families during illness and after a patient's death. All services and accommodations in these facilities are provided at no extra cost to the patient and are part of the service of the statutory as well as private health insurance. As in many other countries, the national level indicates the general direction in which the healthcare system is developing. However, for the patients and caregivers, the regional healthcare situation matters most, and this shows a lot of heterogeneity in Germany. ${ }^{9}$ Due to this regional heterogeneity, this local level should be the driving force for innovation. ${ }^{18} 19$

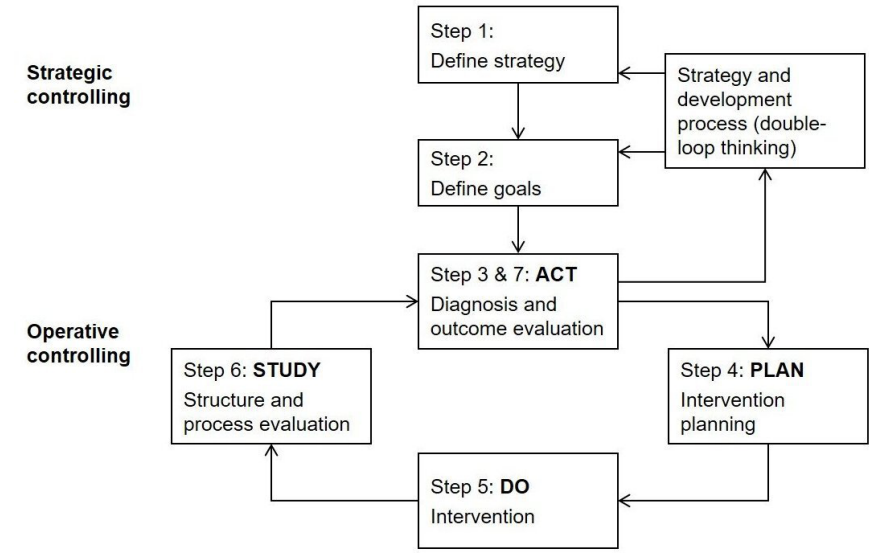

Figure 1 Strategic learning process framed on the Plan-DoStudy-Act (PDSA) cycle Based on Pfaff and Zeike. ${ }^{22}$

Delivering improvements in the quality of healthcare remains an international challenge. Methods such as the Plan-Do-Study-Act (PDSA) cycle have been widely used in healthcare as an attempt to drive such improvements. The PDSA method is an iterative four-step cycle, which includes: (1) identifying a change aimed at improvement, (2) testing this change, (3) examining the success of the change and (4) identifying adaptations and next steps to inform a new cycle. ${ }^{20}$ The fundamental principle is iteration (figure 1). ${ }^{21} 22$ To inform practice, we need practical but still evidence-based solutions that lead to 'satisficing' decisions. ${ }^{23-26}$ Therefore, as a paradigm case for a 1 million inhabitant urban healthcare situation, this paper describes the set-up of a pragmatic quality improvement structure to improve regional end-of-life care. In particular, as the first step of the PDSA cycle, we analyse patient experiences across settings and providers and determinants of satisfaction with care in the last year of life as reported by bereaved relatives.

\section{METHODS}

\section{Setting up the regional structure}

Initiated by three cooperating faculties (Human Sciences; Medicine; and Management, Economics and Social Sciences) of the University of Cologne, Germany, a regional health services research and development structure has been established involving as many relevant partners as possible from medical and social care as well as from health services research. The 'Cologne Research and Development Network' (CoRe-Net) ${ }^{27}$ focuses on the further development of health and social care according to the concept of learning organisations based on a bottom-up approach. Its main aim is to analyse and continuously improve healthcare delivery for vulnerable patient groups by going through PDSA cycles. We invited national and international scientific experts, regional health and social care institutions, patient organisations and statutory health insurance providers to act as CoRe-Net collaboration partners. Within the network, three research projects have been initiated, one focusing 
on patients in their last year of life. For this project entitled 'Last Year of Life Study Cologne (LYOL-C)', ${ }^{28}$ all health and social care practitioners involved in the care of patients in their last year of life (ie, care homes, nursing services, hospices, bereavement cafés, doctors, hospitals, undertakers and the local public health department) as well as providers of grief work in Cologne were contacted for collaboration.

\section{Patient involvement}

Patient representatives were involved in the design and conduct of this research. They worked with us to refine the research question, choice of outcome measures and methods of recruitment. In collaboration with patient representatives, we will design a leaflet for dissemination to distributing to patient groups.

\section{Sample and data collection}

Data were collected in a postbereavement survey as part of the project LYOL-C. Participants were a purposive sample of relatives, friends and voluntary workers (all will be referred to as 'informants' hereafter). Inclusion criteria required informants to be aged 18 years and older and to have recently cared for a person who lived their last year of life in the Cologne area. Deaths of people under the age of 18 years as well as accidental and suspicious deaths were excluded. To ensure maximum variation, informants in this study were recruited in cooperation with health and social care practitioners from Cologne (partners from care homes, nursing services, hospices, bereavement cafés, doctors, hospitals, undertakers and local public health department). We applied two strategies between November 2017 and August 2018 to identify potential informants: (1) questionnaire distribution through cooperating care practitioners through client records by mail or personally and (2) self-selection through public media (newspaper articles, flyers and posters). Informants who were interested in taking part in the survey could request a postal questionnaire from one of the researchers (GD); one reminder was sent. An information sheet describing the study's goals and a response form for opting out of the study were sent with the questionnaire. Informants gave written informed consent before taking part in the survey. All pseudonymously completed questionnaires were returned directly to the research team.

\section{Questionnaire}

The self-complete questionnaire is based on the Views Of Informal Carers - Evaluation of Services-Short Form (VOICES-SF).$^{29}$ It is a validated questionnaire to assess the bereaved relatives' perceptions of the patient's care experiences with providers and services across care settings in the last 3 months of life. VOICES-SF was developed for a nationally representative cross-sectional survey to examine the quality of endof-life care in England, conducted annually for 5 years
(2011-2015), ${ }^{30}$ and has already been used internationally. ${ }^{31-37}$

We developed an adapted German version ('VOICES-LYOL-Cologne') that covers the last 12 months of life and additionally includes the communication of the diagnosis of a life-limiting disease as well as places of care with periods of stay. The questionnaire comprises 106 items and contains skip logic so that informants only respond to questions relevant to the care the patient received. For each specified setting/healthcare provider (home: nursing service, specialist palliative home care team, hospice service, GP and outpatient specialist physicians; care home; hospital [last admission] and inpatient hospice), informants could rate their experiences with care on a four-point scale with respect to the manner of communication, relief of pain, relief of other symptoms, coordination of care, care quality in the last 2 days of life ( $1=y e s, 2=$ rather yes, $3=$ rather no and $4=$ no), respect and dignity ( $1=$ always, $2=$ most of the time, $3=$ some of the time and $4=$ never) and overall satisfaction $(1=$ good, $2=$ rather good, $3=$ rather bad and $4=$ bad). The questionnaire further assesses communication of a life-limiting disease, carer support, unmet needs, financial needs, preferences and decision making, place of death, bereavement support, disease specific and sociodemographic data. Next the informants were asked to provide the settings in which the patients had received care during the last year of life (eg, home, hospital, nursing home, hospice and rehabilitation clinic) and the period of time spent per stay. Data were inserted in a table with chronological order. Objectivity, reliability and validity (content validity as well as divergent and convergent construct validity) were taken into consideration. The VOICESLYOL-C survey has been shown to be useful to assess the quality of care in the last year of life (Dust et al in preparation).

\section{Statistical analyses}

Data were analysed descriptively, and results are presented as mean $\pm \mathrm{SD}$ and count (percentage), respectively. Differences in informants' ratings of care were tested using Mann-Whitney U test for independent samples and Wilcoxon signed-rank test for paired samples.

Second, we performed a logistic regression analysis to explore factors associated with overall satisfaction with care provided in general hospital wards and intensive care units (ICUs). All variables were dichotomised as applied in previous VOICES studies. ${ }^{34} 38-40$ The dependent variable ('Overall, do you feel that the care he/she got from the doctors in the hospital on that admission was: good, rather good, rather bad, bad?') was merged into the most positive response to the question versus all other responses. The independent variables comprised sociodemographic variables of the deceased patients (age, gender, family situation 
and power of attorney) and variables concerning service provision (care by a specialist palliative home care team, treated with respect and dignity by the hospital doctors, relief of pain on last hospital admission, relief of other symptoms on last hospital admission and coordination of care on last hospital admission). First, univariable effect was tested. In a second step, all variables with $p$ value $\leq 0.1$ were entered into a multivariable logistic regression model using a stepwise, forward selection procedure. Results are presented as ORs, corresponding 95\% CIs and $\mathrm{p}$ values.

Data were analysed using SPSS Statistics V.25 and RStudio V.3.5.1 (RStudio Inc, Boston, Massachusetts, USA). Analyses were restricted to individuals with complete data on all variables required for a particular analysis. All presented $p$ values are two sided and considered significant if $\mathrm{p}<0.05$.

\section{RESULTS}

\section{Regional structure: the 'Cologne Research and Development} Network'

CoRe-Net has been established as a long-term and sustainable network, making Cologne a model region for the improvement of health and social care in Germany. Its members consist of three research projects and their collaboration partners. The interdisciplinary cooperation enables the integration of different perspectives and methods. Around 100 partners from health and social care services in Cologne collaborated in the subproject LYOL-C. They represented care homes, nursing services, hospices, bereavement cafés, doctors, hospitals, undertakers and the local public health department. An initial meeting took place to consent the primary outcome and to discuss practical issues (eg, recruitment).

\section{Survey sample}

The questionnaire was returned by 365 informants. Response rate was $21.1 \%$ for postal distribution, $10.3 \%$ for personal distribution and $74.9 \%$ for the selfselection group. A total of 14 questionnaires did not meet the inclusion criteria and had to be excluded. Characteristics of the patients and their informants are presented in table 1. For the 351 deceased patients, the majority of informants were a spouse or a child $(81.8 \%)$, female $(71.5 \%)$ and aged between 50 and 79 years $(77.5 \%)$. Point in time of participation in the survey was $7.6 \pm 4.9$ months after the patient's death. The sample of decedents comprises patients who died between December 2015 and July 2018. It was representative with respect to gender $(47.9 \%$ male) and age (76.5 \pm 13.0 years) compared with full data from the city of Cologne (gender: $50 \%$ male ${ }^{41}$ age: 77.7 years $\left.{ }^{42}\right)$. The main underlying diseases were cancer $(59.5 \%)$ and cardiovascular $(40.5 \%)$,
Table 1 Demographics and characteristics of deceased patients and informants $(\mathrm{N}=351)$

\begin{tabular}{|c|c|}
\hline & $\mathbf{N}(\%)$ \\
\hline \multicolumn{2}{|l|}{ Deceased age at death (years) } \\
\hline $18-29$ & $1(0.3)$ \\
\hline $30-49$ & $6(1.7)$ \\
\hline $50-64$ & $65(18.5)$ \\
\hline $65-79$ & $112(31.9)$ \\
\hline $80+$ & $167(47.6)$ \\
\hline \multicolumn{2}{|l|}{ Deceased sex } \\
\hline Male & $168(47.9)$ \\
\hline Female & $183(52.1)$ \\
\hline \multicolumn{2}{|l|}{ Deceased ethnic group } \\
\hline German & $340(96.9)$ \\
\hline Other & $11(3.1)$ \\
\hline \multicolumn{2}{|l|}{ Deceased family situation* } \\
\hline Had a partner & $163(46.4)$ \\
\hline Lived together with partner & $126(35.9)$ \\
\hline Had children & $168(47.9)$ \\
\hline Lived together with children & $32(9.1)$ \\
\hline Lived together with someone else & $21(6)$ \\
\hline Lived alone & $114(32.5)$ \\
\hline \multicolumn{2}{|l|}{ Someone else had a power of attorney } \\
\hline Yes & $311(88.6)$ \\
\hline No & $33(9.4)$ \\
\hline Do not know & $7(2)$ \\
\hline
\end{tabular}

Illnesses in the last year of life*

$\begin{array}{lc}\text { Cancer } & 209(59.5) \\ \text { Cardiovascular disease } & 142(40.5) \\ \text { Neuropsychological disease } & 115(32.8) \\ \text { Disease of the respiratory system } & 103(29.3) \\ \text { Liver or kidney disease } & 67(19.1) \\ \text { Diabetes mellitus } & 45(12.8) \\ \text { Decubitus ulcer } & 24(6.8)\end{array}$

Informant relation to deceased

$\begin{array}{lc}\text { Spouse } & 149(42.5) \\ \text { Son/daughter } & 138(39.3) \\ \text { Sibling } & 18(5.1) \\ \text { Son/daughter-in-law } & 9(2.6) \\ \text { Other relative } & 17(4.8) \\ \text { Friend } & 12(3.4) \\ \text { Other } & 8(2.3) \\ \text { Informant age (years) } & 2(0.6) \\ 18-29 & 46(13.1) \\ 30-49 & 154(43.9) \\ 50-64 & 118(33.6) \\ 65-79 & 31(8.8) \\ 80+ & \end{array}$

Continued 


\begin{tabular}{ll}
\hline Table 1 Continued & N (\%) \\
\hline \multicolumn{2}{l}{ Informant sex } \\
Male & $100(28.5)$ \\
Female & $251(71.5)$
\end{tabular}

*Multiple responses were possible.

neuropsychological $(32.8 \%)$ and pulmonary (29.3\%) diseases. One-third lived alone.

\section{Transition into the last year of life}

Two hundred and two (63.9\%) of the informants reported that the patient had been told that the disease was leading to death; one-third $(\mathrm{n}=114,36.1 \%)$ indicated that they had not been told. Of those who were told, $44(22.8 \%)$ received this information less than a month before death, but one-third $(n=63,32.6 \%)$ more than a year before death. Hospital doctors were mentioned as breaking the news most often $(n=112$, $60.2 \%)$, followed by outpatient specialist physicians $(\mathrm{n}=29,15.6 \%)$, close relatives $(\mathrm{n}=22,11.8 \%)$, GPs $(\mathrm{n}=15,8.1 \%)$, staff of the specialist palliative home care team $(n=6,3.2 \%)$, staff in the care home $(n=1$, $0.5 \%)$ and staff in a hospice $(\mathrm{n}=1,0.5 \%)$.

\section{Transitions within the last year of life}

Regarding the last year of life, most informants $(n=310,88.6 \%)$ reported that the deceased person spent some time at home and $75(22.4 \%)$ some time in a care home. GPs $(\mathrm{n}=305,87.4 \%)$ and outpatient specialist physicians $(\mathrm{n}=270,77.1 \%)$ mainly provided outpatient care. Furthermore, $157(45.1 \%)$ received care from a home nursing service, 135 (38.8\%) from a specialist palliative home care team and $23(6.6 \%)$ were visited by a hospice service. For 224 (73\%) patients, the informant reported that urgent care provided out of hours was needed. Furthermore, a total of $320(91.4 \%)$ patients stayed in hospital at least once and almost one-fifth $(\mathrm{n}=64,18.8 \%)$ in a hospice.

On average, patients had 3.72 \pm 3.1 transitions between care settings in the last year of life. Each of the five most frequent transitions included hospital care: home to hospital (47.2\%), hospital to home $(27.3 \%)$, care home to hospital $(6.4 \%)$, hospital to hospital $(6.4 \%)$ and hospital to care home $(4.1 \%)$ $(n=255)$. There was an increasing shift from home to the hospital as the main place of care near death. While 12 months prior to death patients spent $85.1 \%$ of their time at home and only $3.1 \%$ in hospital, in the final month of life, they spent $46.3 \%$ of time at home and $30.2 \%$ in hospital (figure 2).

\section{Transition into death}

A percentage of $42.2(n=148)$ died in hospital, as opposed to only $4.2 \%(n=8)$ who wished to die there. One hundred and sixty-one (45.9\%) relatives reported that the decedent

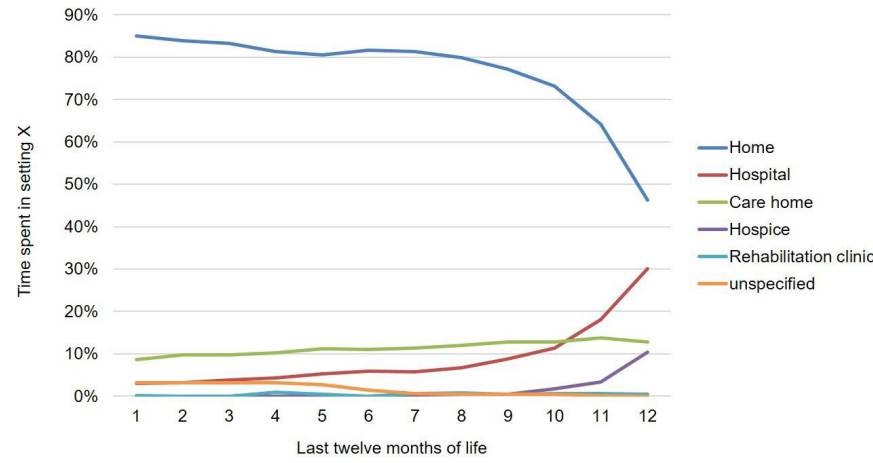

Figure 2 Care settings in the last year of life in Cologne $(n=255)$.

did not express a preference for place of death or that they did not know the preference. The most preferred place of death was home $(\mathrm{n}=129,67.9 \%)$, and this wish was only fulfilled for $27.6 \% \quad(n=97)$ of patients. Nevertheless, the majority of informants stated that the decedent died in the right place $(\mathrm{n}=294,87.2 \%)$, although one-third reported that the patient did not have enough choice about where they died $(\mathrm{n}=94,32.1 \%)$.

\section{Perceived quality of and satisfaction with care in the last year of life}

Regarding informants' views of professionals' way of communicating a life-limiting disease, they were least satisfied with hospital doctors (table 2). Almost one-third stated that the hospital doctor did not communicate in a sensitive and caring way. Differences between ratings of the hospital doctor and non-hospital healthcare providers were statistically significant $(\mathrm{p}=0.003, \mathrm{n}=156)$.

As examples of important quality indicators for care in the last year of life, table 2 further presents informants' ratings of perceived relief of pain and relief of other symptoms, as well as perceived coordination of care differentiated between care settings. It is notable that for symptom control both the home as well as acute hospital setting is rated the most poorly. Only $45.5 \%$ of informants stated that pain relief was good at home and $43.6 \%$ during the last stay in a general hospital ward or ICU. Proportions were even lower for other symptoms with good relief at home reported by $31.8 \%$ and $32.2 \%$ in a general hospital ward or ICU. For perceived coordination of care, the general hospital wards and ICUs rank worst by far with only one-quarter of informants $(25.6 \%)$ who said that the hospital worked well together with other services outside of the hospital. Hospice care was best rated for all three aspects. Eighty per cent of informants reported good pain relief, $67.2 \%$ good relief of other symptoms and $90 \%$ good coordination of care.

Accordingly, informants' perceived overall satisfaction with patient care over the whole last year of life varied significantly depending on the care setting (table 3A). Informants were more likely to rate care provided by hospices $(89.1 \%)$ and the specialist palliative home care team $(86.8 \%)$ as 'good'. Lower proportions of good 
Table 2 Informants' views of professionals' communication style, relief of pain, relief of other symptoms and coordination of care between care settings in the last year of life

\begin{tabular}{|c|c|c|c|c|c|}
\hline \multirow[b]{3}{*}{ Care setting } & \multirow[b]{3}{*}{$\mathbf{N}^{*}$} & \multicolumn{4}{|c|}{ Overall rating } \\
\hline & & Yes & Rather yes & Rather no & No \\
\hline & & n (\%) & n (\%) & n (\%) & n (\%) \\
\hline \multicolumn{6}{|c|}{ Communication of life-limiting disease in a sensitive and caring way } \\
\hline Hospice staff & 1 & $0(0)$ & $1(100)$ & $0(0)$ & $0(0)$ \\
\hline $\begin{array}{l}\text { Specialist } \\
\text { palliative } \\
\text { home care } \\
\text { team }\end{array}$ & 5 & $2(40)$ & $2(40)$ & $1(20)$ & $0(0)$ \\
\hline $\begin{array}{l}\text { Care home } \\
\text { staff }\end{array}$ & 1 & $1(100)$ & $0(0)$ & $0(0)$ & $0(0)$ \\
\hline $\begin{array}{l}\text { General } \\
\text { practitioner }\end{array}$ & 14 & $8(57.1)$ & $6(42.9)$ & $0(0)$ & $0(0)$ \\
\hline $\begin{array}{l}\text { Outpatient } \\
\text { specialist }\end{array}$ & 25 & $9(36)$ & $11(44)$ & $4(16)$ & $1(4)$ \\
\hline Relative & 19 & $16(84.2)$ & $3(15.8)$ & $0(0)$ & $0(0)$ \\
\hline $\begin{array}{l}\text { Hospital } \\
\text { doctor }\end{array}$ & 91 & $34(37.4)$ & $30(33)$ & $13(14.3)$ & $14(15.4)$ \\
\hline \multicolumn{6}{|l|}{ Relief of pain } \\
\hline Hospice & 60 & $48(80)$ & $10(16.7)$ & $2(3.3)$ & $0(0)$ \\
\hline $\begin{array}{l}\text { Hospital: } \\
\text { palliative } \\
\text { care unit }\end{array}$ & 84 & $51(60.7)$ & $23(27.4)$ & $7(8.3)$ & $3(3.6)$ \\
\hline Care home & 66 & $33(50)$ & $26(39.4)$ & $7(10.6)$ & $0(0)$ \\
\hline Homecare & 246 & $112(45.5)$ & $91(37)$ & $33(13.4)$ & $10(4.1)$ \\
\hline $\begin{array}{l}\text { Hospital: } \\
\text { general } \\
\text { ward/ICU }\end{array}$ & 188 & $82(43.6)$ & 78 (41.5) & $21(11.2)$ & $7(3.7)$ \\
\hline \multicolumn{6}{|c|}{ Relief of other symptoms } \\
\hline Hospice & 58 & $39(67.2)$ & $15(25.9)$ & $3(5.2)$ & $1(1.7)$ \\
\hline $\begin{array}{l}\text { Hospital: } \\
\text { palliative } \\
\text { care unit }\end{array}$ & 84 & $39(46.4)$ & $31(36.9)$ & $9(10.7)$ & $5(6)$ \\
\hline Care home & 60 & $28(46.7)$ & $24(40)$ & $8(13.3)$ & $0(0)$ \\
\hline Homecare & 255 & $81(31.8)$ & $113(44.3)$ & $41(16.1)$ & $20(7.8)$ \\
\hline $\begin{array}{l}\text { Hospital: } \\
\text { general } \\
\text { ward/ICU }\end{array}$ & 180 & $58(32.2)$ & $82(45.6)$ & $31(17.2)$ & $9(5)$ \\
\hline \multicolumn{6}{|c|}{ Worked well together with other services } \\
\hline Hospice & 50 & $45(90)$ & $3(6)$ & $0(0)$ & $2(4)$ \\
\hline $\begin{array}{l}\text { Hospital: } \\
\text { palliative } \\
\text { care unit }\end{array}$ & 54 & 35 (64.8) & $12(22.2)$ & $4(7.4)$ & $3(5.6)$ \\
\hline Care home & 68 & 43 (63.2) & $18(26.5)$ & $4(5.9)$ & $3(4.4)$ \\
\hline Homecare & 244 & $125(51.2)$ & 72 (29.5) & 34 (13.9) & $13(5.3)$ \\
\hline $\begin{array}{l}\text { Hospital: } \\
\text { general } \\
\text { ward/ICU }\end{array}$ & 133 & 34 (25.6) & 24 (18) & $32(24.1)$ & $43(32.3)$ \\
\hline
\end{tabular}

*Number of patients for whom the corresponding question was responded. ICU, intensive care unit.

ratings were given for the hospital palliative care units $(68.5 \%)$, hospice services $(68.4 \%)$, GPs $(56.7 \%)$, care homes $(50 \%)$, outpatient specialist physicians $(47.6 \%)$ and nursing services $(47.3 \%)$. They were least satisfied with the care provided in acute hospitals (general wards and ICUs), which was rated 'good' by $41.3 \%$ and received the most 'bad' $(9.6 \%)$ ratings. We tested the differences in informants' reports of satisfaction with acute hospital care versus all other health and social care practitioners (eg, hospital general ward/ICU vs hospice; table 3B). Differences were statistically significant in comparison with care provided by hospice $(\mathrm{p}=0.003, \mathrm{n}=41)$, specialist palliative home care team $(\mathrm{p}<0.001, \mathrm{n}=76)$, palliative care unit $(\mathrm{p}<0.001, \mathrm{n}=297)$, home hospice service $(\mathrm{p}=0.033$, $\mathrm{n}=12)$ and the GP $(\mathrm{p}=0.009, \mathrm{n}=179)$.

\section{Determinants of satisfaction with care in an acute hospital setting}

Since care provided by general hospital wards and ICUs were rated worst compared with all other health and social care practitioners in the last year of life, we explored the determinants of satisfaction with care delivered in these hospital wards and units. Table 4 shows the results of the multivariable logistic regression analysis. Two variables were found to associate satisfaction with hospital care, while all other variables did not reach significance any more. First, the model indicated that the feeling that the patient was treated with respect and dignity by the doctor was associated with an almost 24-fold increase in the likelihood of being satisfied. Second, the impression that the hospital worked well together with other services outside the hospital was associated with an eightfold increase of being satisfied.

\section{DISCUSSION}

\section{Principal findings}

This study is the first to our knowledge to set up a pragmatic PDSA cycle to improve regional care in the last year of life. Embedded in a regional health services research and development structure, we comprehensively analysed patient experiences with care in the last year of life from the bereaved relatives' perspectives. For symptom control, both home as well as acute hospital setting was rated the most poorly. Hospitals were reported as the main player for diagnosing a progressive condition, for being involved in most transitions during the last year of life and being the most frequent place of death despite all home palliative and hospice services available in Cologne. Yet, satisfaction was lowest with care provided in an acute hospital setting, which was determined by the feeling of not being treated with respect and dignity and the impression that hospitals did not work well together with other services. Based on this first step of the PDSA cycle, two interventions were developed to continue the cycle.

\section{Strengths and weaknesses}

Most end-of-life care studies focus on a single care setting or are restricted to the dying phase, the last weeks of life or an underlying diagnosis. VOICES surveys include multiple settings to disaggregate findings according to 
Table 3A Informants' overall satisfaction with care provided by health and social care practitioners in the last year of life

\begin{tabular}{|c|c|c|c|c|c|}
\hline \multirow[b]{3}{*}{ Care setting } & \multicolumn{5}{|c|}{$\begin{array}{l}\text { 'Overall, how would you rate the care he/she } \\
\text { got in the last year of life?' }\end{array}$} \\
\hline & & Good & $\begin{array}{l}\text { Rather } \\
\text { good }\end{array}$ & $\begin{array}{l}\text { Rather } \\
\text { bad }\end{array}$ & Bad \\
\hline & $\mathbf{N}^{*}$ & n (\%) & n (\%) & n (\%) & n (\%) \\
\hline Hospice & 64 & $57(89.1)$ & $5(7.8)$ & $0(0)$ & $2(3.1)$ \\
\hline $\begin{array}{l}\text { Specialist palliative } \\
\text { home care team }\end{array}$ & 129 & $112(86.8)$ & $13(10.1)$ & $2(1.6)$ & $2(1.6)$ \\
\hline $\begin{array}{l}\text { Hospital (doctor): } \\
\text { palliative care unit }\end{array}$ & 89 & $61(68.5)$ & $22(24.7)$ & $3(3.4)$ & $3(3.4)$ \\
\hline Hospice service & 19 & $13(68.4)$ & $6(31.6)$ & $0(0)$ & $0(0)$ \\
\hline $\begin{array}{l}\text { General } \\
\text { practitioner }\end{array}$ & 282 & $160(56.7)$ & 75 (26.6) & $36(12.8)$ & $11(3.9)$ \\
\hline Care home & 72 & $36(50)$ & $26(36.1)$ & $10(13.9)$ & $0(0)$ \\
\hline $\begin{array}{l}\text { Outpatient } \\
\text { specialists }\end{array}$ & 229 & $109(47.6)$ & 76 (33.2) & $30(13.1)$ & $14(6.1)$ \\
\hline Nursing service & 146 & $69(47.3)$ & $59(40.4)$ & 15 (10.3) & $3(2.1)$ \\
\hline $\begin{array}{l}\text { Hospital (doctor): } \\
\text { general ward/ICU }\end{array}$ & 208 & $86(41.3)$ & $76(36.5)$ & $26(12.5)$ & $20(9.6)$ \\
\hline
\end{tabular}

*Number of patients for whom the corresponding question was responded. ICU, intensive care unit.;

Table 3B Comparison of informants' overall satisfaction with acute hospital care versus other health and social care practitioners

\begin{tabular}{lcc}
\hline & \multicolumn{2}{c}{$\begin{array}{l}\text { Acute hospital care (general } \\
\text { ward/ICU) versus other care } \\
\text { setting* }\end{array}$} \\
\cline { 2 - 3 } Care setting & $\mathbf{N}$ & P value† \\
\hline Hospice & 41 & $0.021 \ddagger$ \\
$\begin{array}{l}\text { Specialist palliative home care } \\
\text { team }\end{array}$ & 76 & $<0.001 \ddagger$ \\
$\begin{array}{l}\text { Hospital (doctor): palliative care } \\
\text { unit }\end{array}$ & 297 & $<0.001 \S$ \\
Hospice service & 12 & $0.268 \ddagger$ \\
General practitioner & 179 & $0.069 \ddagger$ \\
Care home & 52 & $0.543 \ddagger$ \\
\hline Outpatient specialists & 135 & $1.0 \ddagger$ \\
\hline Nursing service & 101 & $0.679 \ddagger$ \\
\hline
\end{tabular}

*Compares informant's overall rating of the last hospital stay (doctor) in acute hospital setting (general ward or ICU) with the overall rating of every other care setting (eg, hospital general ward/ICU vs hospice). $\dagger P$ values are adjusted using Bonferroni correction for multiple comparisons.

‡Wilcoxon signed-rank test for paired samples; comprises patients who experienced both forms of care.

$\S M a n n-W h i t n e y \mathrm{U}$ test; comprises patients who either received care in a hospital general ward/ICU or in a palliative care unit. $\mathrm{ICU}$, intensive care unit.

specific setting type. Nevertheless, the instrument only evaluates the last 3 months of life. ${ }^{29}$ Within this study, we used an adapted German version of the VOICES-SF, which was expanded to the last 12 months of life and included the communication of a life-limiting diagnosis.
Table 4 Logistic regression analysis of satisfaction with hospital care

\begin{tabular}{llc}
\hline Variable & OR $(95 \%$ Cl) & P value \\
\hline $\begin{array}{l}\text { Respect and dignity by the } \\
\text { hospital doctor }\end{array}$ & $23.80(7.503$ to 75.498$)$ & $<0.001$ \\
$\begin{array}{l}\text { Hospital worked well } \\
\text { together with other services } \\
\text { outside the hospital }\end{array}$ & $8.37(2.141$ to 32.71$)$ & 0.002 \\
\end{tabular}

Number of cases $=124$; cases correctly classified $=85.5 \%$; $\mathrm{AUC}=0.904$

This instrument enables the reconstruction of the entire last year of life of patients, irrespective of the underlying diagnosis, to assess the provision and quality of care of all health and social care practitioners involved in patients' care. Our findings demonstrate the feasibility of collecting patient experiences reported by proxy-respondents across multiple care settings.

In Germany, there is no national register available that could be used to identify participants. Therefore, a population-based survey was not feasible, and the sample of decedents represented in this study was a purposive sample. Due to the recruitment strategy, patients from palliative care services are over-represented. Nevertheless, it appropriately reflected the age and gender distribution of people dying in the city of Cologne. ${ }^{41} 42$

We used a retrospective research design and asked bereaved relatives to act as proxies for the deceased patients. Relatives' reports of care experiences after the death of a loved one are an important outcome measure to determine the quality of end-of-life care. ${ }^{14}$ This method is, of course, not without its limitations, especially in relation to memory, the impact of bereaved relatives' feelings and the concordance between patient and proxy reports. ${ }^{43} 44$ A few studies examined these concerns and found that respondents were more accurate in recalling salient events and that satisfaction was mainly determined by service characteristics. ${ }^{45} 46$ A review on the validity of proxies' responses found that the level of agreement was good on service evaluations and observable symptoms but lower for subjective symptoms such as pain. ${ }^{47}$ The retrospective approach has a long history in the conducting of end-of-life-care research. It bypasses the difficult task of identifying the terminally ill, avoids putting an additional burden on very sick participants and minimises missing data due to poor functional status. It furthermore creates a clear time frame for the purpose of comparing settings of care. ${ }^{48}$

The present study was conducted in Cologne, a city with 1 million inhabitants in Germany. It is not clear whether these results are transferable to other regions, rural as well as urban areas. Nevertheless, this study describes a pragmatic template based on patient experiences (PDSA cycle), which can be used to determine improvement priorities by other regions. 


\section{Comparison with existing literature}

We found substantial differences in the reported satisfaction with care depending on the care setting. Informants were significantly more satisfied with quality of care provided in hospices compared with other care settings. Unfortunately, only a small number of patients will ever be admitted to hospice. In Germany, approximately $5 \%$ of patients, most of them cancer patients, die in hospice. ${ }^{49}$ In the present study, home was the place where people spent most of their time during their last year of life. Informants reported of insufficient symptom control when being cared for at home. Reasons may include a lack of home care provider expertise, limits on service allocation, fragmentation of multidisciplinary services and a considerable workload for many family practitioners with regards to home visit frequency and duration. ${ }^{31050-52}$ Hospitals were the most frequent place of death, with the highest levels of dissatisfaction. These results are similar to those from other VOICES studies carried out in Western countries. ${ }^{132} 34$ Previous studies also identified psychosocial rather than physical factors leading to dissatisfaction with care. A lack of personal care and dignity has been reported to cause patients to feel 'devalued' or 'dehumanised'. ${ }^{53}$ Being involved in decisions and discussing any worries were also described as predictors of satisfaction with hospital care. ${ }^{38}$ International studies have shown that there is still a discrepancy between current best practice recommendations and observed clinical reality, for example, with regard to the recognition of a patient's transition into the last year of life, identifying a patient's palliative care needs and aspects of shared decision making. ${ }^{54}$ Reasons for this may lie in the obvious life-saving culture of hospitals where the norm is to prevent death by whatever means are necessary. Furthermore, it may also be due to the increasing time and cost pressure put on hospitals without these institutions having established standards for patients who will die within the foreseeable future ${ }^{55}$ Since almost $30 \%$ of all hospital patients are expected to be in their last year of life, ${ }^{56}$ our findings stress the importance of a further integration of palliative care into acute care hospitals. Strategies for integrating palliative care into a country's healthcare system have been developed. In 2007, the WHO published a public health strategy that includes advice and guidelines for governments on priorities and how to implement national palliative care programmes. ${ }^{57}$ Furthermore, international experts in palliative care and cancer care formulated written statements regarding how integrated palliative care can be operationalised. ${ }^{58}$ In Germany, the evidence-based guideline 'Palliative care' was published in 2015 to promote quality end-of-life care by all healthcare professionals. This palliative care guideline presents the fundamental principles of palliative care which, in organ-specific guidelines, would be repetitive and/or not able to be dealt with in a comprehensive manner. ${ }^{7}$

\section{Implications and future research}

Based on the research of a regional working group, it was found that acute hospital care needs to be changed in order to improve care in the last year of life. Our regional priority for action now is improvement of care in acute hospitals, two new projects have started: first how to identify patients in their last year of life and initiate communication, and second, how to improve care during the dying phase according to quality indicators of our national guideline. ${ }^{759}$ Results and further improvement projects will be discussed in this regional working group, and repeating this survey in 2 years will be able to-hopefully-measure regional achievements. This study starting a PDSA cycle can therefore serve as an example for determining regional improvement priorities based on patient experiences.

\section{Author affiliations}

${ }^{1}$ Faculty of Medicine and University Hospital, Department of Palliative Medicine, University of Cologne, Cologne, Germany

${ }^{2}$ Faculty of Medicine and University Hospital, Center for Integrated Oncology Aachen Bonn Cologne Dusseldorf (CIO ABCD), University of Cologne, Cologne, Germany

${ }^{3}$ Faculty of Medicine and University Hospital, Clinical Trials Center(ZKS), University of Cologne, Cologne, Germany

${ }^{4}$ Faculty of Medicine and University Hospital, Center for Health Services Research, University of Cologne, Cologne, Germany

${ }^{5}$ Faculty of Human Sciences and Faculty of Medicine, Institute for Medical Sociology, Health Services Research, and Rehabilitation Science, University of Cologne, Cologne, Germany

${ }^{6}$ Faculty of Medicine and University Hospital, Institute of Medical Statistics and Computational Biology, University of Cologne, Cologne, Germany

${ }^{7}$ Faculty of Health and Medicine, Division of Health Research, University of Lancaster, Lancaster, UK

${ }^{8}$ Faculty of Educational and Social Sciences, Department of Educational Science, Heidelberg University of Education, Heidelberg, Germany

Correction notice This article has been corrected since it was published. The equal contributorship has been added in the paper.

Acknowledgements This study was made possible by the collaborative efforts of health and social care practitioners in Cologne. We further thank everyone who contributed their time and expertise, in particular the study participants, the CoRe-Net coapplicants and our research assistant Christian von Reeken.

Collaborators The CoRe-Net coapplicants: Professor Dr Christian Albus, Department of Psychosomatics and Psychotherapy, Faculty of Medicine (FM), University Hospital Cologne (UHC); Professor Dr Lena Ansmann, Department of Health Services Research, School of Medicine and Health Sciences, Carl von Ossietzky University Oldenburg; Professor Dr Frank Jessen, Department of Psychiatry and Psychotherapy, FM, UHC; Professor Dr Ute Karbach, Sociology in Rehabilitation, Faculty of Rehabilitation, Technical University Dortmund; Professor Dr Ludwig Kuntz, Department of Business Administration and Health Care Management, Faculty of Management, Economics and Social Sciences (FMESS), University of Cologne (UoC); Dr Ingrid Schubert, PMV Health Care Research Group, FM, UoC; Professor Dr Frank Schulz-Nieswandt, Institute for Sociology and Social Psychology, FMESS, UoC; and Professor Dr Stephanie Stock, Institute for Health Economics and Clinical Epidemiology, FM, UHC.

Contributors RV and GD are joint first authors and act as guarantors. RV, JS and $\mathrm{CR}$ are principal investigators and responsible for the study design, project management, data analysis and dissemination. GD and NiS designed the survey instrument and collected data. GD cleaned and analysed data. SH, SP, NaS and HP contributed to study design, data analysis and dissemination. HP is principal investigator of CoRe-Net. NaS coordinates CoRe-Net. All authors read and approved the final manuscript.

Funding This work was supported by the German Federal Ministry of Education and Research, grant number \#01GY1606.

Competing interests None declared. 
Patient and public involvement Patients and/or the public were involved in the design, or conduct, or reporting, or dissemination plans of this research. Refer to the Methods section for further details.

\section{Patient consent for publication Not required.}

Ethics approval All procedures for this study were approved by the Ethics Commission of the Faculty of Medicine of the University of Cologne, Germany (\#17188). Participants gave written informed consent before taking part.

Provenance and peer review Not commissioned; externally peer reviewed. Data availability statement Data are available on reasonable request.

Open access This is an open access article distributed in accordance with the Creative Commons Attribution Non Commercial (CC BY-NC 4.0) license, which permits others to distribute, remix, adapt, build upon this work non-commercially, and license their derivative works on different terms, provided the original work is properly cited, appropriate credit is given, any changes made indicated, and the use is non-commercial. See: http://creativecommons.org/licenses/by-nc/4.0/.

\section{ORCID iDs}

Gloria Dust http://orcid.org/0000-0003-3119-0997

Nadine Scholten http://orcid.org/0000-0002-7793-7745

Julia Strupp http://orcid.org/0000-0003-3135-2693

\section{REFERENCES}

1 Hanratty B, Lowson E, Grande G, et al. Transitions at the end of life for older adults - patient, carer and professional perspectives: a mixed-methods study. Southampton, UK: NIHR Journals Library, 2014: 130.

2 Addington-Hall JM, O'Callaghan AC. A comparison of the quality of care provided to cancer patients in the UK in the last three months of life in in-patient hospices compared with hospitals, from the perspective of bereaved relatives: results from a survey using the VOICES questionnaire. Palliat Med 2009;23:190-7.

3 Bainbridge D, Seow H. Palliative care experience in the last 3 months of life: a quantitative comparison of care provided in residential Hospices, hospitals, and the home from the perspectives of bereaved caregivers. Am J Hosp Palliat Care 2018;35:456-63.

4 Addington-Hall JM, Bruera E, Higginson IJ, et al. Research methods in palliative care. Oxford University Press, 2007.

5 Bone AE, Gao W, Gomes B, et al. Factors associated with transition from community settings to hospital as place of death for adults aged 75 and older: a population-based mortality Follow-Back survey. J Am Geriatr Soc 2016;64:2210-7.

6 Cardona-Morrell M, Kim J, Turner RM, et al. Non-beneficial treatments in hospital at the end of life: a systematic review on extent of the problem. Int J Qual Health Care 2016;28:456-69.

7 German Cancer Society, German Cancer Aid, AWMF. Palliative care for patients with incurable cancer short version 2.0: AWMFregistration number 128/0010L, 2019. Available: https://www. leitlinienprogramm-onkologie.de/leitlinien/palliativmedizin/ [Accessed 5 Nov 2019]

8 Gomes B, Calanzani N, Gysels M, et al. Heterogeneity and changes in preferences for dying at home: a systematic review. BMC Palliat Care 2013;12:7.

9 Bertelsmann Stiftung. Palliative care: Available services do not (yet) meet patient needs - Expansion requires clear regulatory strategy: Spotlight Healthcare. Gütersloh: Bertelsmann Stiftung, 2015.

10 Oishi A, Murtagh FEM. The challenges of uncertainty and interprofessional collaboration in palliative care for non-cancer patients in the community: a systematic review of views from patients, carers and health-care professionals. Palliat Med 2014;28:1081-98.

11 Temel JS, Greer JA, Muzikansky A, et al. Early palliative care for patients with metastatic non-small-cell lung cancer. $N$ Engl J Med 2010;363:733-42.

12 Smith TJ, Temin S, Alesi ER, et al. American society of clinical oncology provisional clinical opinion: the integration of palliative care into standard oncology care. J Clin Oncol 2012;30:880-7.

13 Bainbridge $\mathrm{D}$, Seow $\mathrm{H}$. Measuring the quality of palliative care at end of life: an overview of data sources. Health Aging Clin Care Elder 2016;8:9-15.

14 Lendon JP, Ahluwalia SC, Walling AM, et al. Measuring experience with end-of-life care: a systematic literature review. J Pain Symptom Manage 2015;49:904-15.

15 Mayland C, Williams E, Ellershaw J. How well do current instruments using bereaved relatives' views evaluate care for dying patients? Palliat Med 2008;22:133-44.
16 Kupeli N, Candy B, Tamura-Rose G, et al. Tools measuring quality of death, dying, and care, completed after death: systematic review of psychometric properties. Patient 2019;12:183-97.

17 The Economist Intelligence Unit. The 2015 quality of death index: ranking palliative care across the world, 2015. Available: https:// eiuperspectives.economist.com/sites/default/files/2015\%20EIU\% 20Quality\%20of\%20Death\%20Index\%200ct\%2029\%20FINAL.pdf [Accessed 5 Nov 2019].

18 Braithwaite J. Changing how we think about healthcare improvement. BMJ 2018;361:k2014.

19 Hämel K, Ewers M, Schaeffer D. Health care and regional disparities [Article in German]. Z Gerontol Geriatr 2013;46:323-8.

20 Taylor MJ, McNicholas C, Nicolay C, et al. Systematic review of the application of the plan-do-study-act method to improve quality in healthcare. BMJ Qual Saf 2014;23:290-8.

21 Pietrzak M, Paliszkiewicz J. Framework of strategic learning: the PDCA cycle. Management 2015;10:149-61.

22 Pfaff H, Zeike S. Controlling Im Betrieblichen Gesundheitsmanagement: Das 7-Schritte-Modell. Wiesbaden: Gabler Verlag, 2019.

23 Parker AM, Bruine de Bruin W, Fischhoff B. Maximizers versus satisficers: decision-making styles, competence, and outcomes. Judgment and Decision making 2007;2:342-50.

24 Schwartz B, Ben-Haim Y, Dacso C. What makes a good decision? robust Satisficing as a normative standard of rational decision making. J Theory Soc Behav 2011;41:209-27.

25 Simon HA. Rational decision making in business organizations. The American economic review 1979;66:493-513.

26 Simon HA. Making management decisions: the role of intuition and emotion. Academy Manage Perspect 1987;1:57-64.

27 Karbach U, Ansmann L, Scholten N, et al. [Report from an ongoing research project: The Cologne Research and Development Network (CoRe-Net) and the value-based approach to healthcare]. Z Evid Fortbild Qual Gesundhwes 2018;130:21-6.

28 Strupp J, Hanke G, Schippel N, et al. Last year of life study Cologne (LYOL-C): protocol for a cross-sectional mixed methods study to examine care trajectories and transitions in the last year of life until death. BMJ Open 2018;8:e021211.

29 Hunt KJ, Richardson A, Darlington A-SE, et al. Developing the methods and questionnaire (VOICES-SF) for a national retrospective mortality follow-back survey of palliative and end-of-life care in England. BMJ Support Palliat Care 2019;9:e5.

30 Office for National Statistics. National survey of bereaved people (voices): information paper. 13, 2016

31 Ross L, Neergaard MA, Petersen MA, et al. Measuring the quality of end-of-life care: development, testing, and cultural validation of the Danish version of views of informal carers' evaluation of servicesshort form. Palliat Med 2018;32:804-14.

32 Beccaro M, Caraceni A, Costantini M, et al. End-of-life care in Italian hospitals: quality of and satisfaction with care from the caregivers' point of view-results from the Italian survey of the dying of cancer. $J$ Pain Symptom Manage 2010;39:1003-15.

33 Frey R, Williams L, Trussardi G, et al. The views of informal carers' evaluation of services (voices): toward an adaptation for the New Zealand bicultural context. Palliat Support Care 2017;15:67-76.

34 O'Sullivan A, Alvariza A, Öhlen J, et al. Bereaved family members' satisfaction with care during the last three months of life for people with advanced illness. Healthcare 2018;6:E130.

35 Pungchompoo W, Suwan P, Kunapun S, et al. Experiences of symptoms and health service preferences among older people living with chronic diseases during the last year of life. Int J Palliat Nurs 2019;25:129-41.

36 Ingleton C, Morgan J, Hughes P, et al. Carer satisfaction with end-oflife care in Powys, Wales: a cross-sectional survey. Health Soc Care Community 2004;12:43-52.

37 Donnelly S, Prizeman G, Coimín Diarmuid Ó, et al. Voices that matter: end-of-life care in two acute hospitals from the perspective of bereaved relatives. BMC Palliat Care 2018;17:117.

38 Young AJ, Rogers A, Dent L, et al. Experiences of hospital care reported by bereaved relatives of patients after a stroke: a retrospective survey using the VOICES questionnaire. J Adv Nurs 2009;65:2161-74.

39 Hunt KJ, Shlomo N, Addington-Hall J. End-of-life care and achieving preferences for place of death in England: results of a populationbased survey using the VOICES-SF questionnaire. Palliat Med 2014;28:412-21

40 Hunt KJ, Shlomo N, Addington-Hall J. End-of-life care and preferences for place of death among the oldest old: results of a population-based survey using VOICES-Short form. J Palliat Med 2014:17:176-82. 
41 Stadt Köln - Amt für Stadtentwicklung und Statistik. Kölner Statistische Nachrichten - 1/2019: Statistisches Jahrbuch Köln 2018. Köln, Stadt Köln, 2019.

42 Stadt Köln - Amt für Stadtentwicklung und Statistik. Kölner Zahlenspiegel. Köln: Stadt Köln, 2018.

43 Baddeley AD. Human memory: theory and practice. 515. Boston, MA: Allyn and Bacon, 1990.

44 Bower GH. Mood and memory. Am Psychol 1981;36:129-48.

45 Fakhoury W, McCarthy M, Addington-Hall J. Determinants of informal caregivers' satisfaction with services for dying cancer patients. Soc Sci Med 1996;42:721-31.

46 Mathiowetz NA. Forgetting events in autobiographical memory: findings from a health care survey Rockville1988. Available: http:// www.asasrms.org/Proceedings/papers/1988_029.pdf [Accessed 5 Nov 2019].

47 McPherson CJ, Addington-Hall JM. Judging the quality of care at the end of life: can proxies provide reliable information? Soc Sci Med 2003;56:95-109.

48 Teno JM. Measuring end-of-life care outcomes retrospectively. $J$ Palliat Med 2005;8:s-42-s-49.

49 Dasch B, Blum K, Gude P, et al. Place of death: trends over the course of a decade: a population-based study of death certificates from the years 2001 and 2011. Dtsch Arztebl Int 2015;112:496-504.

50 Bainbridge D, Brazil K, Krueger P, et al. Evaluating program integration and the rise in collaboration: case study of a palliative care network. J Palliat Care 2011;27:270-8.

51 Bee PE, Barnes P, Luker KA. A systematic review of informal caregivers' needs in providing home-based end-of-life care to people with cancer. J Clin Nurs 2009;18:1379-93.
52 Pochert M, Voigt K, Bortz M, et al. The workload for home visits by German family practitioners: an analysis of regional variation in a cross-sectional study. BMC Fam Pract 2019;20:3.

53 Rogers A, Karlsen S, Addington-Hall J. 'All the services were excellent. it is when the human element comes in that things go wrong': dissatisfaction with hospital care in the last year of life. $J$ Adv Nurs 2000;31:768-74.

54 Milnes S, Orford NR, Berkeley L, et al. A prospective observational study of prevalence and outcomes of patients with gold standard framework criteria in a tertiary regional Australian hospital. BMJ Support Palliat Care 2019;9:92-9.

55 Gott M, Ingleton C, Bennett MI, et al. Transitions to palliative care in acute hospitals in England: qualitative study. BMJ 2011;342:d1773.

56 Clark D, Armstrong M, Allan A, et al. Imminence of death among hospital inpatients: prevalent cohort study. Palliat Med 2014;28:474-9.

57 Stjernswärd J, Foley KM, Ferris FD. The public health strategy for palliative care. J Pain Symptom Manage 2007;33:486-93.

58 Payne S, Hughes S, Wilkinson J, et al. Recommendations on priorities for integrated palliative care: transparent expert consultation with international leaders for the InSuP-C project. BMC Palliat Care 2019;18:32.

59 The Gold Standards Framework. Acute Hospital programme: summary of evidence of effectiveness, 2016. Available: http://www. goldstandardsframework.org.uk/cd-content/uploads/files/GSF\% 20Summary\%20of\%20EValuation\%20\%20Acute\%20Hospitals\% 20Sept\%202016\%281\%29.pdf [Accessed 5 Nov 2019]. 